\title{
CO-WIFE CONFLICT AND CO-OPERATION ${ }^{1}$
}

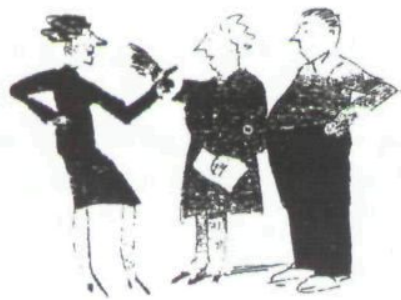

William Jankowiak

Monika Sudakov

Benjamin C. Wilreker

University of Nevada, Las Vegas

Conventional wisdom holds that the polygynous family system is as sexually and emotionally satisfying as a monogamous one. Ethnographic accounts of 69 polygynous systems, however, provide compelling evidence that the majority of co-wives in a polygynous family prefer pragmatic co-operation with one another while maintaining a respectful distance. Moreover, there often is a deep-seated feeling of angst that arises over competing for access to their mutual husband. Co-wife conflict in the early years of marriage is pervasive, and often marked by outbursts of verbal or physical violence. Co-wife conflict may be mitigated by social institutions, such as sororal polygyny and some form of "social security" or health care. Material wealth may be divided more or less equally, but as a husband's sexual attention (a primary source for increased fertility) and affection cannot always be equitably distributed, there is ongoing and contentious rivalry among co-wives. (Co-wife conflict, jealousy, co-operation, pair bond)

Cultural anthropologists generally assume that humans are highly adaptable to a wide range of life circumstances. Less accepted is the qualification that "cultural models can have significant psychic costs for individuals" (Shore 1996:49). The assumption of enormous adaptability has also been challenged by many anthropologists (see Brown 1990 for overview) concerned with the topics of reproduction and family intimacy. For example, some (Ekvall 1968; Levine and Silk 1997) find that the fraternal polyandrous marriage system is unstable largely due to sexual and emotional factors, rather than economic considerations. Research on co-wife relationships in polygynous families find them to be emotionally unsatisfactory for the majority of participants (Al-Krenawi 1999; Al-Krenawi and Graham 1999; Chisholm and Burbank 1991; Hill and Hurtado 1996; Jankowiak 2001; Meekers and Franklin 1995; Strassman 1997; Ware 1980). However, other researchers (Borgerhoff-Mulder 1992; Kilbride 1994; Madhavan 2002; Mason 1982) report that under certain circumstances, women living in a polygynous family system enjoy material and emotional satisfaction.

This article examines the effect of structural and psychological factors on co-wife conflict and co-operation. Specifically, it seeks to determine whether a pair-bond impulse is present in every culture, and if so, whether it undermines co-wife co-operation. Unlike previous studies of co-wife conflict and co-operation that focus only on one culture or a single geographical region, we have expanded the scope to include co-wife interactions in cultures from all over the world. We also identify the material, social, and emotional factors that can undermine or strengthen co-wife bonds. Examining how individuals respond to the polygynous family allows for a more thorough exploration of the polygynous family's divisiveness. To this end, we use the reasons for co-wife conflict as a means to identify anxieties within the polygynous family. 


\section{EXPLANATIONS FOR CO-WIFE CONFLICT AND CO-OPERATION}

The conceptual frameworks of behavioral ecology and evolutionary psychology are two of the more predominant explanatory schemes used to account for variation and continuities in polygynous family life. Although the two frameworks can form a unified theory, most researchers emphasize either the cultural variations or the continuity in their data. The behavioral ecologist Monique Borgerhoff-Mulder $(1988,1989,1992)$ argues that material and related structural factors exert an enormous impact on shaping the quality of co-wife interaction, and that the degree to which a woman is materially dependent on her husband determines her willingness to co-operate or compete with a co-wife over material resources and reproductive considerations. From this it follows that the greater a wife's material dependence on her husband, the more frequent and intense will be her conflicts with a co-wife. If co-wife conflicts arise more from structural factors, there may be societies where they are muted or absent.

Borgerhoff-Mulder's $(1989,1992)$ research finds that because women's material dependence on their husbands is markedly reduced among East African herders (e.g., Masai, Samburu, Kipisgis, Sebei), there is a marked reduction in co-wife conflict combined with a noticeable increase in co-wife co-operation. This is indeed the case, but we have a different understanding of its cause. We argue that reduced conflict arises less from a woman's decreased material dependence on a husband than from her sexual and emotional satisfaction.

In contrast to the behavioral ecology framework, the evolutionary psychology perspective focuses less on variation than on the identification of underlying universals that affect an individual's reaction to kinds of human interaction. It also has sought the presence of sex-linked differences in men's and women's mateselection criteria (Symons 1979), reaction to a spouse's infidelity (Shackelford et al. 2004), and parenting styles (Hrdy 1999). This research also has explored traits common to both men and women (Brown 1990; Barrett, Dunbar, and Lycett 2002). Although the human pair bond is often implied in the literature, there is no attempt to document where it also constitutes a human universal. Some cultural anthropologists (Bohannan 1995; Harrell 1997) suggest that the pair bond is a byproduct of community social organization. Others suggest that an impulse to form a pair bond is present in every type of society, even those that strive to deny its existence (de Munck and Korotayev 1999; Gray et al. 2004; Jankowiak and Fischer 1992; Jankowiak 1995; Kaplan and Lancaster 2003; Peachey 2001; Schlegel n.d..).

"Pair bond" refers to an attachment based on a shared sexual intimacy and at times on a deep sense of mutual belonging. It further assumes that men and women have sexual and emotional desires best fulfilled within a dyadic relationship that can endure. In this way, reproductive interest and pair-bond attachment are intertwined. A pair bond is thus not a casual relationship, nor is it necessarily lifelong in duration. The impulse to form a pair bond is ubiquitous, albeit in different proportions, even in societies that discourage its formation; e.g., those with arranged marriages or the polygynous family. People in a viable pair bond assume that sexual fidelity is important for both partners. They tend, therefore, to 
be involved in monitoring and preventing their partner's extramarital sexual behavior (Jankowiak and Ramsey 2000; Jankowiak, Nell, and Buckmaster 2002).

In most societies, the pair bond is associated with a desire for long-term mating or marriage. There are exceptions. It was common, for example, among the upper classes of early-nineteenth-century Russia to form intense love bonds outside of marriage, as Tolstoy portrayed in his fiction. A pattern of emotional and reproductive bifurcation is also found among the Masai and Samburu herders of East Africa, some Middle Eastern Bedouin groups, and in numerous Amazonian cultures (Beckerman and Valentine 2002; Gregor 1985; Lizot 1985; Crocker and Crocker 2004). This suggests that men and women's sexual, emotional, and material interests structure co-wife interaction. Yet there are few analyses of co-wife interaction that explore whether the presence of a pair-bond inclination promotes co-wife conflict and thereby undermines co-operative exchanges in polygyny.

In not attending to the importance of the pair bond, anthropologists have overlooked a factor that can produce co-wife resentment, hostility, and conflict. Due to differences in reproductive interests, co-wife conflict is seldom simple or fleeting. This is not to suggest that other behavioral ecology factors do not influence a woman's decision or willingness to remain in a polygynous family. Issues such as birth order, the number of children a woman has, the presence of an ethos of sharing, a woman's physical limitations, the need for child-care assistance, or related reproductive concerns may all be determining factors for the willingness of women in some subsistence systems to stifle or mute their desire for sexual and emotional exclusivity. However, the presence of these ecological factors does not negate the importance of the pair bond as a potential disrupting factor that can undermine co-wives' ability to get along with each other.

\section{HYPOTHESES}

Our first hypotheses are linked to an overarching behavioral ecology model:

1) Co-wife conflict and co-operation are a function of the degree of social complexity or stratification present within a society. The greater the complexity in a society, the greater the possibility for envy and resentment to arise.

2) A corollary hypothesis states that co-wife conflict is related to the degree a woman is dependent on her husband for material support. From this it follows that co-wife conflict will be more prevalent in societies where women are responsible for material production. Thus, African societies where women form the core laboring group should have the least conflict compared to societies where women are not the primary source of production.

3) There will be a relationship between the type of descent system and the frequency with which a woman is willing to enter into some form of socialsecurity and health-care relationship with a co-wife. In societies having matrilineal descent, women can rely more on their female kin, and should therefore show less incentive to enter into these relationships with co-wives than women who are in patrilineal and patrilocal systems. From this it follows that there will be more health-care and social-security relationships reported for matrilineal than for patrilineal systems. 
4) The needs (e.g., subsistence and care) of a woman's own children will her primary concern. Thus, co-wife conflict will arise over real and imagined inequalities in the distribution of material resources among their children.

5) As women age, co-wife rivalry should ebb in favor of pragmatic forms of co-operation. There will therefore be less competition between postmenopausal and reproductively nubile women.

6) The pair-bond hypothesis assumes that humans have a tendency to form exclusive sexual and emotional dyadic relationships with a spouse or lover. It then follows that co-wife conflict will arise out of a woman's effort to obtain sexual and emotional satisfaction. Therefore, co-wife conflict should be present in all societies, regardless of social complexity.

\section{METHODS}

There is a lacuna in the literature on polygynous co-wife interaction. ${ }^{2}$ For example, there is no study that documents the relationship between a woman's age, the number of children she has, her ethnicity compared to that of the incoming wife, the presence or absence of a helping spouse, and the availability of child support. Without knowing how these factors interact with one another, it is difficult to analyze the conditions of co-wife co-operation and conflict.

Our primary information comes from cultures identified in Murdock and White's (1969) Standard Cross-Cultural Sample that had one or more case studies of co-wife co-operation or conflict. We were able to supplement these data with information reported from similar cultural settings. Cases were not included from Murdock and White's Standard Cross-Cultural Sample where ethnographers wrote about polygyny but did not discuss co-wife interaction or relationships. Cultures were not included where there was a clear bias (e.g., missionary accounts) against polygyny or where specialists recognized the source as faulty or incorrect. Ambiguous cases were discarded.

Despite these restrictions, we were able to find 69 cultures where the ethnogra-pher discussed in some depth co-wife interactions. Information for eleven of the 69 cultures came from interviews with the ethnographer who had worked in the same or a similar type of society. Respondents were asked a set of questions similar to those used to code the written texts. In addition, they were asked to estimate the proportion of co-wife relations that were close and supportive, distant and indifferent, and outright hostile.

Given the sample size, our study remains exploratory. It requires other ethnographers to return to the issue of factors promoting co-wife conflict and co-operation with a new conceptual framework. Although small, the sample's remarkable consistency in women's responses suggests that there are commonalities in the way women respond to the presence of a co-wife. Further, the uniformity in women's responses indicates that our findings are robust, and that the sample set is representative.

Most of the ethnographic cases come from Africa $(n=39)$, where polygyny continues to be practiced, albeit with diminishing frequency. We also looked at 30 non-African cultures. ${ }^{3}$ The observations are therefore not confined to Africa, but have worldwide implications for understanding co-wife relationships. The few and 
brief reports on harem polygyny we considered to be unrepresentative of the institution, and excluded these from the study.

Whenever the institution of sororal polygyny is discussed, ethnographers emphasize the ubiquity of co-wife co-operative bonds. This does not mean that sisters do not experience personal antagonism and sexual jealousy. Sororal polygyny has not been systematically studied, so it is not clear if these relationships are free of sexual jealousy or if sexual jealousy is only manifested covertly. Our sample did not have a single ethnographic account of an antagonistic relationship between sister-wives. It appears that the rank order established when they were siblings in the same natal family carries over into the marriage and serves as an effective means for muting co-wife conflict. Further, sisters may have developed close emotional bonds with one another that serve as an alternative to the husband-wife bond. Whatever the reason, we concur with Chisholm and Burbank (1991), who suggest that sororal polygyny should be treated as a separate institution from that of nonsororal polygyny. We sought to control for this factor by coding sororal and nonsororal interactions separately. Our analysis is based entirely on nonsororal co-wife interaction.

Survey questionnaires (Ware 1980) consistently note that co-wife conflicts arise through competition over material resources. In contrast, in-depth ethnographic analysis, especially when conducted by female researchers (Allen 1974; Burbank 1994; Colson 1961; Meekers and Franklin 1995; Moran 1990; Whyte 1979), often commented on the sexual and emotional ambiguity that women feel about sharing their husbands with co-wives. These reports indicate that one reason for co-wife conflict is a desire to monopolize a husband's attention or sexual services. The presence of an "institutionalized lover" was designated if the ethnographer reported that it was culturally condoned and common for both spouses to have extramarital affairs. ${ }^{4}$

Clearly, co-wife conflict ranges from endemic conflict and persistent resentment and hostility, through pragmatic co-operation spiked with incidents of intense hostility, to completely harmonious relations. We rated this continuum along a sliding scale from zero for complete harmony to three for endemic conflict. We derived the level of conflict from interaction reported among co-wives within the first five or so years of a marriage.

Cultures were classified as having endemic conflict if the ethnographer reported that co-wife relationships were generally characterized by deep-seated contempt, manifested routinely in acts of physical and/or verbal aggression. If the ethnographer reported one or more instances of verbal or physical hostility between co-wives but made no mention of the frequency or duration, the culture was classified as pragmatic co-operation, with intense eruptions of conflict. If the ethnographer reported that co-wife conflict was present, but that co-operative relationships were prevalent, the culture was classified as pragmatic co-operation, with occasional hostility. When the ethnographer noted that co-wife relationships were supportive, affectionate, and free of conflict, the culture was classified as harmonious. No ethnographer reported this level of co-operation present for any culture. In contrast, it is common for ethnographers to note that husband-wife relationships in a majority of cultures were supportive, affectionate, and thus relatively conflict free. The fact that no ethnographer working in a nonsororal 
polygynous family system reported this suggests that co-wife conflict and resentment constitute a unique sphere of tension and hostility.

A criticism of previous observations of co-wife conflict has been the excessive reliance on evidence of folk aphorisms or proverbs. Such lively sayings as "the dubious joys of [Santal] plural marriage," "a pair of dogs always bite," "pecking hens never agree" (Archer 1964), or "a compound of [Bangwa] wife is like a handful of highly poisonous snakes" (Spencer 1998:76) are suggestive. It is striking that animalistic imagery is used to characterize the co-wife character all around the world. These linguistic expressions suggest that co-wives lack kindness, consideration, and empathy, and strongly suggest beastliness. Cattell (2003) calls this evidence the "myth of co-wife hostility." To control for this tendency, we have relied on anthropologists' comments on the overall quality of co-wife relationships as well as the examination of examples of conflict or co-operation reported in the literature. The degree of conflict or co-operation within a particular culture is thereby determined through the use of multiple indicators

Schlegel's (1972) cross-cultural study of how authority structures promote or mute co-wife conflict in matrilineal societies found conflict reduced in societies in which women were dominated by brothers as opposed to husbands. Because the ethnographic description of co-wife interaction in Schlegel's sample is thin (as she relied strictly upon indirect measures such as presence or absence of witchcraft accusations and related folk idioms), she concluded that the absence of folk idioms about the "evil" or "problems" of living with a co-wife suggested that relationships were more cordial and less fractious. Our sample set has eleven matrilineal cultures where the ethnographer discussed co-wife interaction, and five of these cultures are brother dominated. We found no reduction in the level of reported co-wife conflict. The difference in our data may arise from our use of different criteria to assess presence or absence of co-wife conflict. We relied on ethnographic accounts that discuss specific co-wife interaction, whereas Schlegel relied on more indirect indicators.

Because ethnographers have not analyzed the daily interactions between co-wives, the overall quality of co-wife relationships is seldom observed closely. We assumed that unless otherwise noted, minor co-operative exchanges, such as giving food or water to a co-wife's children or borrowing or lending incidental food stuffs would be part of the pragmatics of daily living in the same household or in separate but relatively nearby households (i.e., within the same compound or within eyesight). In order to determine if co-operative exchanges extended beyond this minimum, we coded those actions that were beyond low-cost co-operative exchanges. If present, these included co-wives cooking food for one another, attending to one another when ill, or attending funerals of each other's close kin. Such behaviors suggest an emotional involvement between co-wives (Mason 1982).

\section{RESULTS}

1) We found no support for the behavioral-ecology hypothesis that the subsistence system of a culture predicts the intensity of co-wife conflict. The 
relationship between subsistence and the intensity of co-wife conflict is weak, and the inverse of that predicted by the model. The behavioral-ecology model suggests that conflict should increase with increasing social stratification, but it slightly decreases with increased social complexity. Horticultural societies (a mean of $2.45)$ are highest, followed by hunter-gatherer societies (2.33), pastoral societies (2.20), and agricultural societies (a mean of 2.12). These numbers are not statistically significant. Co-wife conflict is prevalent throughout every subsistence system.

2) We found no indication that women's access to the means of production has any bearing on co-wife co-operation or conflict. The mean conflict score of agricultural African societies where women formed the core of the farming labor force $(n=24)$ was 2.13 . The mean score of nonagricultural polygynous African societies where women have limited access to the means of production $(n=15)$ was 2.20. This difference is not significant. Beyond Africa, we compared polygynous agricultural societies to polygynous societies using other subsistence systems. Since our non-African sample is small $(\mathrm{n}=30)$, we lumped all non-African polygynous societies together. Non-African agricultural societies where women are divorced from the means of production $(n=9)$ score 2.78 on our conflict scale, while non-African societies that use other means of subsistence $(n=21)$ score 2.57. Once again, the difference of .21 is not significant. The overall lower conflict scores in Africa (mean 2.15) compared to the rest of the world (mean 2.63) may be a product of our limited sample size.

3) No significant relationship was found between a particular descent system and the adoption of a health-care or social-security arrangement. Three out of eleven matrilineal societies examined ( 27 per cent) utilized some form of a healthcare/social-security arrangement. Thirty-one per cent (15 out of 49) of patrilineal societies have a similar arrangement. The Aka pygmies are the only foraging culture to establish some form of mutual health-care assistance. This does not mean that such an arrangement is not present among other foragers, only that it has not been reported in the literature. Bilateral industrialized polygynous societies use the social-security arrangement at approximately the same rate as agricultural communities organized around an ideology of unilineal descent.

4) There is qualified support for the "my child's interest first" hypothesis. In 24 of 69 cultures (or 35 per cent), defending or advancing children's interests was recorded as a reason for co-wife conflict. Further, advancing a child's interests was overwhelmingly ( 23 out of 24 occasions) noted in conjunction with other motives for co-wife conflict.

5) Aging does affect the frequency of co-wife conflict and co-operation. The data demonstrate that women are more willing to enter into pragmatic and supportive relationships as they age. This pattern was found present in 19 of 44 societies (or 43 per cent) that discuss the life cycle in our sample.

6) There is strong confirmation for the pair bond hypothesis as an explanation for co-wife conflict. Ethnographers in 60 of 69 cultures (or 89 per cent) reported that sexual and emotional access was a cause of co-wife conflict. This was especially so in the early stages of a plural marriage. 


\section{CASE ILLUSTRATIONS}

Although material resources may be divided equally among co-wives, affection cannot be equally divided. The underlying cause of co-wife hostility arises out of competing reproductive interests. We found that women's effort to gain sexual access (which is related to fertility concerns) and emotional intimacy in the polygynous family is often the foremost concern.

1) The problem with polygamy, according to one Truk Islander, is that "the first wife is angered if the husband divides his favors evenly. But the second wife gets angry if he doesn't" (Goodenough 1978:123).

2) Colson (1961:63) observed that Tonga women have a strong inclination to form an exclusive relationship with their husband that is incompatible with polygyny. She observed that "if one wife succeeds in her aim, it is only at the expense of others," while "men expect their wives to be jealous and to quarrel over their husbands' favors. It is believed that co-wives often resort to various love medicines in an attempt to gain first place with the husband and that they may use sorcery to kill a hated co-wife or her children."

3 ) In the past, among the matrilineal Tallensi, co-wives were certain to have differences and quarrels. Fortes (1969:107) remarks that "men say that wives will quarrel with the husband and with their co-wives over the sexual attentions of their common husband than for any other cause. . . Though a woman cannot prevent her husband from having a clandestine lover, she will resent it as a slight on her sexual attractions if she finds out, and makes life uncomfortable for him in revenge."

4) The importance of exclusivity is voiced by a 50 -year-old Swazi woman who in the 1960s told an ethnographer of her intense ambivalence about sharing her husband with her older sister. The woman asserted, "It is not good for a man to have more than one wife because a man does not support the women or one woman. At times he gives you a sweet and has favorites and doesn't care about the others. I did like having a co-wife-if I did not like it, I would have run away, but there were no chances for this when I got married and it was one of the Swazi customs if a man wanted his wife's sister, he had to have her and I had no choice. . . [N]o one likes to have a co-wife" (Allen 1974:527).

5) Jealousy among Dogon co-wives (Calame-Griaule 1986:383) is "not limited to sexual matters but extends to all forms of attention and marks of affection (e.g., gifts) that a husband may show one or another. . . Co-wives translate their sexual jealousy into fierce insults whose secret goal is to cause the husband's distaste for the other wife: 'wide (or swollen cunt),' 'cunt like a hyena's foot,' 'runny cunt like flowing water,' [the] last insinuation [implying] that the woman has many lovers."

6) Among the West African Fulbe, sexual rivalry remains a strong motivation for co-wife hostility and mutual violence. A 44-year-old Fulbe woman, suspicious that her husband had already taken another wife, vowed that "I will continue with sex till death in order to prevent my husband from taking another wife" (Madhavan 2002:78).

7) In spite of the norm that Bamanan women should accept the arrival of a cowife, combined with the pragmatic need of the co-wife's support for successful 
farming, sexual jealousy is rampant. The refusal to associate, accompanied with the use of black magic, is commonly articulated in speech. Bamanan women often despise the arrival of a co-wife, as evidenced by the spoken fear that they are being set aside for a newer and prettier woman. "Such is the force of their resentment," Madhavan (2002:78) writes, that "it is common for a senior wife to successfully force the departure of a co-wife through use of black magic, thereby causing considerable anxiety for the remaining co-wife."

8) The tacit pair bond is evident in the assertion of a Marachi woman of Kenya that she chose her own husband. There is also widespread acknowledgment that men often become highly selective in the distribution of their time and material resources, as illustrated by this revealing comment:

You know my husband does not have much land. But my co-wife has taken it all for her own cultivation. For myself, I borrow land from five different people to grow food. My co-wife has seven children and I have six. We want those children to learn so that they can get jobs and help us. I have two children in secondary school, but my husband barely helps to pay school fees. He uses all his money to drink and help my co-wife. Maybe he only wants to help her children to learn. It is only because I work so hard, selling my crop surplus, raising some livestock and distilling local rum that my children can go to school. My co-wife has always been difficult. My husband used to help me more, but now he drinks. At least he does not disturb me or beat me, I have suffered a lot in this home, but I will not give up. I chose my own husband and here is where I will die. (Whyte 1979:143)

9) Among the Iatmul, it is not uncommon for a co-wife to attack a newly arrived wife with knives, shovels, spears, sticks, or anything at hand. Silverman (pers. comm.) says that "co-wife fighting is the most vicious fighting I have ever witnessed in the village. And it was the most frequent. Eventually, they tend to reach a sort of hostile 'pragmatic indifference.' Sometimes this is eased when they live in separate residences (i.e., one wife lives with her natal family), which some men say is a good solution." It is also the case that some co-wives get along "since that is the best way to stay on good terms with the husband. In other words, the husband often reacts aggressively toward the co-wife who is most aggressive to her rival, and so co-wives may come to realize that they are in the best position in the household overall with respect to their husband when they become allies, an amicable front." Silverman concludes, "In my experience co-wives begin the relationship with enormous, often physical rage, and then slip into indifference. I would say that very few co-wives form any type of friendship. Most, over time, move into a state of indifference."

10) Among the Ojibwa, Landes (1969:66-69) reports that it is usually the shaman who is distinguished by polygyny. She reports that an Ojibwa woman who matures in a culture with a strong romantic-love ethos (de Munck and Korotayev 2000) dislikes polygyny, as her self-esteem is punctured when her husband selects another wife presumably because she is more charming. In short, it undermines cultural expectations of the pair bond.

11) Among the Cubeo Indians of the Northwest Amazon, the desire for emotional exclusivity is the principal factor behind much co-wife conflict. As Goldman (1963:145) writes, "polygynous households are rather turbulent ... the wives quarrel and [complain] against one another to the husband, accusing one another of laziness. The first wife taunts her colleague as being a mere second 
wife. The second retorts that she would not have been chosen if he really cared for the first wife."

12) Among the Bella Coola, "a chief's wives always lived in the same house, and it is said that disputes were frequent ... [so] the chief endeavored to prevent jealousy by providing each woman with a special bedroom and sleeping for a single night with each in order. One informant had two wives when a young man, and he found that the only way to avoid constant bickering was by sleeping in one bed, between them. The evidence seems clear that the plurality of wives was usually the cause of considerable friction" (Mcllwraith 1992:404).

13) The importance of exclusivity for women is a primary reason behind most Alorese co-wife conflict. "Whenever a new wife enters the family it is common [for Alorese women to] exchange insults for a time and then begin pulling, tugging, and beating at each other. Immediately all the women of the village become involved. Each wife has a certain number of belligerent allies, and in addition there is always a large group of women who try to separate the combatants but who manage in their role of peacemakers to land some very effective blows. A whole village may be in a turmoil of struggling women waging a shifting warfare in the mud or dust of the dance place for as long as from two to four hours" (Du Bois 1960:110-11).

14) Hamadeh's (1999:141-73) case study of his youth in a polygamous Bedouin household reports that he often heard co-wives that he thought got along rather well still bickering "about whom their late husband had favored. Sometimes, they laughingly teased each other over who was going to die first and thus gain the privilege of lying in the grave closest to their husband." He notes further that "the vast majority of urban co-wives feel hatred toward one another," whereas rural co-wives who must coexist in order to survive develop a "variety of feelings that ranged between the extremes of love to hate" (Hamadeh 1999:155). He remarks that most rural co-wives adopt a more muted and indifferent-appearing posture toward one another. They also feel a fondness for each other. The author remembers the co-wives telling one another "how lost they would feel if the other was away for the day or more."

\section{DISCUSSION}

Our data suggest that the majority of young women react to the arrival of a new co-wife with feelings of fear, anger, sadness, and loss. This sentiment is expressed through a variety of culturally acknowledged and measurable behaviors; for example, witchcraft accusations, statements of concern for the welfare of children, accusations of favoritism, demands of greater access to the husband, complaints of being sexually ignored, outbreaks of physical or verbal abuse, and expressing an intention to divorce or actually doing so. Except for sororal polygynous marriages, polygynous families in two foraging populations (e.g., Aka pygmies and Mardu aborigines) and a few East African herding cultures (e.g., Masai, Samburu, and Kipsigis), we suspect that close, co-operative co-wife relationships are seldom the norm. With the exception of Hewlett (pers. comm.), who works among the Aka pygmies, no ethnographer estimated or speculated that the rate was higher than 25 per cent. It appears that most co-wives prefer to 
maintain a respectful distance and try to live their lives separately from each other. The fact that many cannot do so necessitates that women work to develop a tolerance for, and in some instances a preference for, life in the polygynous family.

For most women, the reaction to the arrival of a co-wife (who is not a sister) is anxiety, frustration, and aggression. On the other hand, Hewlett (pers. comm.) found that an Aka pygmy woman's response to an incoming co-wife is determined by factors such as the number of children she has and by her concern for help when she is ill. Newly married Aka women without children are prone to attack a rival, whereas women (especially those in their late twenties and early thirties) with children look at the incoming wife as a possible source of health-care assistance, if not friendship. From our cross-cultural survey, the Aka young woman's response is not unique. Around the world, most young women are loath to share a husband.

Support for this interpretation is the evidence in our sample for high levels of co-wife conflict in 61 of 69 (or 88 per cent) of cultures, whereas we found evidence for a low degree of conflict in eight of the 69 (or 12 per cent) of the cultures. Clearly, for the majority of women, the polygynous family is a civic family and not an emotional home. When co-wives form an affection-based relationship, it appears to be the exception and not the norm.

Table 1: Subsistence and Intensity of Conflict

\begin{tabular}{||l|r|r|l|r||}
\hline & Endemic & $\begin{array}{l}\text { Underlying } \\
\text { Resentment }\end{array}$ & $\begin{array}{l}\text { Pragmatic Co-operation/ } \\
\text { Occasional Conflict }\end{array}$ & Harmonious \\
\hline Hunter/Gatherer (6) & 4 & 0 & 2 & 0 \\
Horticultural (13) & 9 & 3 & 1 & 0 \\
Pastoral (10) & 2 & 6 & 2 & 0 \\
Agricultural (33) & 12 & 19 & 2 & 0 \\
Urban (7) & 4 & 2 & 1 & 0 \\
\hline
\end{tabular}

Table 2: Descent System and Intensity of Conflict

\begin{tabular}{||l|r|l|l|r||}
\hline & Endemic & $\begin{array}{l}\text { Underlying } \\
\text { Resentment }\end{array}$ & $\begin{array}{l}\text { Pragmatic Co-operation/ } \\
\text { Occasional Conflict }\end{array}$ & Harmonious \\
\hline Matrilineal (11) & 8 & 3 & 0 & 0 \\
Patrilineal (49) & 16 & 26 & 7 & 0 \\
Bilateral (9) & 7 & 1 & 1 & 0 \\
\hline
\end{tabular}

We did find specific circumstances that promoted a reduction in co-wife conflict. These included: sororal marriage, co-wife relationships between a barren and a fertile woman, co-wife relationships between a postmenopausal and a fertile woman, social security concerns, the need for a work mate, lowered sexual and 
emotional dependency on a husband, friendships, and the presence of institutionalized lovers. We also found that whenever the ethnographer $(n=44)$ noted exceptions to co-wife conflict, aging and health-care concerns were predominant in 19 of 44 (or 43 per cent) of the cultures, followed by assistance with daily chores, and friendship. These exceptions to co-wife conflict are found more often in stratified societies than in the more egalitarian hunting-and-gathering societies. In horticultural societies husbands may use physical violence to compel co-wives to get along, or at least to promote some order through maintaining a kind of "respectful tolerance."

Another factor that contributes to reducing co-wife conflict is a woman's reproductive status. None of the ethnographers $(n=7)$ who wrote on the topic reported conflict between barren and fertile co-wives. Barren women, probably because their marginal status makes it difficult for them to make demands for greater spousal exclusivity, overwhelmingly strive to form close bonds with cowives and their children, thereby avoiding becoming divorced. Reproductive vitality, women's age in the marriage, and the presence or absence of children influence a woman's willingness to enter into or avoid forming some kind of pragmatic co-operative relationship with another co-wife.

We also found that age difference between co-wives may lower a woman's competitive attitude toward an incoming wife. In many cultures the senior wife is reported to be overbearing and cruel to an incoming junior wife. However, in other cultures $(n=19)$, women establish a verbal contract, or a social-security relationship organized around a fictive kinship nomenclature (e.g., a formalized mother-daughter term of address) to assure that the older woman will not undermine an incoming wife's access to their husband. In exchange for the first wife's tolerance, the younger woman will care for the older as she ages. This arrangement constitutes a personally negotiated indigenous retirement system.

A concern with personal health is of paramount importance to women in numerous societies. Feldman-Savelsberg (1999:133) points out that "although fights among co-wives are a major source of women's unhappiness and vulnerability to witchcraft attacks, many monogamous women [perhaps with rosecolored glasses], yearn for a . . co-wife who could help when illness strikes." A possible exception to this is with the East African herders and farmers, where older women are inclined to live together in a common compound as a kind of retirement community, and thus engage in more frequent co-operative exchanges. We did not find another culture where this was the normative practice.

Levine (1962:44-45) observed a strong correlation between "residential proximity of co-wives to witchcraft attribution and sorcery ... [that arises out] of personal aggression which is highest amongst co-wives-in spite of the occasional friendship that is created." He noted that when the wives live apart and hardly see each other, evidence of witchcraft is nonexistent. We found that household distance did not entirely diminish co-wife resentment. When co-wives live some walking distance from one another, it is easier to ignore a co-wife's existence. Yet hostility remains in a woman's imagination. Clearly, co-wives who live far apart cannot readily engage in fights, but they can and do continue to worry about who may be obtaining a disproportionate share of material and sexual resources. If they reside near each other, they are capable of more direct 
confrontations, but are more likely to use covert means to express hostility. Distance does nothing to mute co-wife resentment, and may even increase it.

The significance of sexual and emotional access to the husband has received little attention in the literature on the polygynous family. In our sample, it is clearly an important factor in the vast majority of co-wife conflict (54 of 60 cultures, or 90 per cent). The polygynous family system does not diminish a woman's sexual or emotional needs, or her willingness to assert her interest over a rival. This does not mean that gaining material resources or advancing children's interests are not likewise a woman's goals. However, demands for material resources or the needs of children often are a metaphor for sexual and emotional sustenance.

Table 3: Causes of Co-Wife Conflict in 60 Cultures

\begin{tabular}{||l|c|c||}
\hline & $\mathrm{n}($ out of 60) & Per Cent \\
\hline Child and Resources & 18 & 30 \\
Resources & 33 & 55 \\
Sexual/emotional & 54 & 90 \\
\hline
\end{tabular}

The significance of this finding is best revealed through contrasting the degree of co-wife hostility with the quality of spousal conflict found in a monogamous family. There are few societies where the majority of monogamous conjugal relationships would be classified as endemically hostile. In most societies there are couples whose marriage is hostile, but it is rare for an entire society to be characterized this way. To suggest that marital or family conflict is at one time or another present within every kind of marriage system misses the central point: the intensity and duration of marital conflict varies by family system, with co-wife conflict as manifested by contempt and acute indifference having greater duration than between spouses in a monogamous marriage system.

From a normative perspective, co-wives should form closer friendships and enter into friendly transactions with co-wives who are linked as kin in a larger family system. For most women, co-operation is less about establishing affective solidarity than it is about solving the pragmatics of daily living. We found that most women ceased engaging in co-operative relationships when there was no longer any practical need to do so. In this way, co-operative relationships are based on a calculated exchange or direct reciprocity. It is important not to confuse performance congeniality with true camaraderie. The fact that some women request a co-wife as a work partner does not mean they will form a close bond or that the requesting woman even prefers this type of relationship. A request for one does not presume a preference for the other.

For the majority of women, the more common posture ranges from pragmatic co-operation to indifference to outright hostility. That no more than 25 per cent of co-wives in any given community form close friendships, with the exception of the Aka pygmies, is significant. These friendships are dyadic in orientation. 
However, the formation of a friendship bond does not appear to reduce the negative sentiments held toward other co-wives. We suspect that for most cultures there are closer friendships between non-co-wives than there are between co-wives. Since ethnographers have not investigated friendship formation inside and outside a polygynous family in any systematic way, this remains only a conjecture.

If co-wife conflict arises from struggles over sexual and emotional desires and material resources, then it is significant that the most commonly cited examples of co-wife co-operation are between a reproductively fertile woman and either an infertile woman or one near the end of her reproductive capability. In eliminating reproductive concerns, one of the more contentious sources that often divide women is also eliminated, thereby enabling the formation of more enduring affective bonds. This factor may account for the diminished intensity in Aka co-wife hostility. Young Aka women without children seldom accept a co-wife. Upon reaching middle age, however, they are more open to accepting and, most important, working with a co-wife as a valued ally who is no longer regarded as a rival. The intensity of a "woman's desire to enter into a pair bond differs with age. The exclusive focus on the pair bond may diminish over the years as women expand their social and emotional networks, especially those with grown children" (Schlegel, pers. comm.). Our data support this observation.

Further support for the central importance of the pair bond can be found in those communities that tolerate extramarital affairs for both sexes. We found a strong relationship between acceptance of extramarital affairs by nonspouses and a reduction of reports about co-wife conflict. Intimacy as a factor for conflict is less likely when the husband is not a wife's only outlet for sexual and emotional satisfaction. The importance of sexual and emotional involvement for the reduction in co-wife hostility, and thus co-wife conflict, is evident among East African herders, the Mardu (Australian aborigines), and the Mossi of Burkina Faso, and may provide an alternative explanation to the behavioral ecology perspective. These societies have been characterized as having low co-wife conflict and high co-operation. One explanation (Borgerhoff-Mulder 1992) has been that women are less dependent upon their husbands for material support, and therefore co-operate with one another in order to survive.

An alternative explanation is that the husband is not valued as the primary source of sexual and emotional fulfillment. These cultures have institutionalized extramarital sexual and emotional affairs. This outlet provides women with an alternative means of achieving personal satisfaction. For example, Fiske (pers. comm.) reports that among the Mossi, men and women usually form a love bond with a secret adolescent lover before they marry. Some form of sexual and emotional involvement is maintained with this lover for most of their lives. Among East African herders, men and women usually have several lovers, which allow women an avenue for personal satisfaction. The behavioral ecology model's singular emphasis on a woman's material dependence or independence from her husband cannot completely account for the reduction in co-wife conflict in this region. Instead, there is an additional qualification that whenever the community tolerates extramarital affairs (or institutionalized lovers), struggles among 
co-wives for sexual and emotional intimacy with their common husband are not as prominently noted as when institutionalized lovers are unavailable.

Our survey found that in ten of the sixteen cultures where extramarital affairs are common for both sexes, there is a lower frequency of co-wife conflict. The presence of an alternative sexual and emotional outlet may also account for the marked decrease in co-wife conflict reportedly present in sororal polygynous marriages. Sisters who have established strong bonds of intimacy prior to marriage are less focused on dominating access to their common husband. For them, the husband is a secondary player in the enhancement of their well-being. Why the need to form a pair bond is more muted in sororal polygyny is beyond the scope of our data. Perhaps biological sisters find greater emotional satisfaction with one another and thus have no need to form an exclusive attachment with their common husband. Or the absence of sororal conflict may reflect a gap in the ethnographic literature more than the absence of sister-wife conflict.

\section{CONCLUSION}

This project attempted to probe the ethnographic literature for evidence of co-operation and conflict in multiple marriages. But ethnographers seldom discuss the frequency or contexts of co-wife co-operation (Madhavan 2002), thereby conveying the impression that co-wife conflict is ubiquitous. Our survey of the ethnographic literature did find numerous pragmatic acts of co-operation that also included cases of lifelong friendship between some co-wives. In a careful review of the ethnographic record, however, we also found a recurrent motif of strident co-wife hostility. Invariably, first wives tended to react to the arrival of a new cowife with fear, anger, sadness, and loss. We also discovered that co-wives use various strategies to make the best of what is for many an emotionally trying experience.

Although some of these strategies are more successful than others in alleviating a woman's anxiety, with the exception of a few societies, this anxiety never completely leaves. We found that focusing exclusively on the structural factors first noted by behavioral ecologists that may generate co-wife conflict and/or promote co-operation is incomplete. For a complete picture, women's sexual and emotional needs must be considered. This requires incorporating the findings from evolutionary psychology, especially as they pertain to humankind's preference to enter into and establish a pair bond.

Further, contrary to the behavioral ecology assumption that there can be a society in which the majority of co-wife relationships are conflict free, we found that whenever the ethnographer discussed co-wife relationships in depth, conflict was reported as present for the majority of relationships in that culture. Further, we found that co-wife co-operation is usually organized around exchanges designed to meet situational needs, such as health care, and this is just as important, if not more so, than finding a partner who will assist them in performing their daily chores.

Finally, we found women's sexual desire and reproductive interests paramount factors in promoting co-wife conflict. If polygyny creates elementary families centered on one man, it also creates women looking for exclusivity with that man. 
This fact accounts for much of co-wife friction and deep-seated resentment. By the same token, a woman's ability to adjust to life in a polygynous family varies with age. That a woman, under some circumstances, enters into pragmatic co-operation and even friendship with a co-wife should not undermine the significance of our finding that women in their early reproductive years are the most resentful of the arrival of a co-wife. Our findings go against the conventional wisdom that a polygynous family as a marital system is as satisfying as any other. ${ }^{5}$

\section{NOTES}

1. For support and assistance in collecting the data used in this study, we thank Jim Bell, Jiemin Bao, Don Brown, Vicki Burbank, Pat Draper, Tom Gregor, Paul Conklin, Jerry Earles, Carol Ember, Mel Ember, Vanessa Fong, Hill Gates, Terry Hays, Pamela Feldman-Savelsberg, Alan Fiske, Elliot Fratkin, Nancy Flower, Alma Gottlieb, Betty Harris, Karl Heider, Jon Holtzman, Barry Hewlett, Bonnie Hewlett, Daniel LeBas, Mary Moran, Lee Munro, Tom Paladino, Len Plotnicov, Eric Silverman, Bilinda Straight, Aud Talle, Bob Tonkinson, and Elizabeth Witt.

2. Initial studies of the polygynous family sought to understand the factors necessary for its formation (Ember 1985; Harrell 1997; Levine 1962; Low 2000; and White and Burton 1988), its persistence as a productive system (Clignet 1970; Goody 1976, 1990), and as a reproductive system (Borgerhoff-Mulder 1988, 1989, 1992). Other researchers sought to probe life within the polygynous family through examining the meanings, conflicts, co-operative exchanges, and reconciliations that people undertake in a polygynous family (Bennion 1998; Altman and Ginat 1996; Dupire 1968; Jankowiak 2001; Kilbride 1994; Soloway 1990; Ware 1980).

3. The sample set consists of 69 polygynous cultures in Africa (39), Asia (7), the Pacific (13), North America (3), and South America (7).

4. The fact that community norms tolerate extramarital affairs does not mean that the spouse does. Women around the world respond with anger or deep-seated pain whenever they become aware of such sexual betrayal (Jankowiak, Nell, and Buckmaster 2002).

5. What remains to be determined is whether the dissatisfactions of polygynously married women are confined to their role of wife. It is possible that polygynous marriage systems are better for divorced women with children or elderly women. A comparison of monogamous marriage systems and polygynous marriage systems is needed to make an evaluation concerning the relative happiness of participants in each system (Vanessa Fong, pers. comm.).

\section{BIBLIOGRAPHY}

Al-Krenawi, A. 1999. Women of Polygamous Marriages in Primary Health Care Centers. Contemporary Family Therapy 21(3):417-30.

Al-Krenawi, A., and J. Graham. 1999. The Story of Bedouin-Arab Women in a Polygamous Marriage. Women's Studies International Forum 22(5):497-509.

Allen, C. 1974. Dimensions of Swazi Households in Rural and Urban Areas. Ann Arbor.

Altman, I., and J. Ginat. 1996. Polygamous Families in Contemporary Society. New York.

Archer, W. G. 1964. Tribal Law and Justice: A Report on the Santal. New Haven.

Barrett, L., R. Dunbar, and J. Lycett. 2002. Human Evolutionary Psychology. New York.

Beckerman, S., and P. Valentine (ed.). 2002. Cultures of Multiple Fathers: The Theory and Practice of Partible Paternity in Lowland South America. Gainesville.

Bennion, J. 1998. Women of Principle: Female Networking in Contemporary Mormon Polygyny. New York.

Bohannan, P. 1995. How Culture Works. New York.

Borgerhoff-Mulder, M. 1988. The Relevance of the Polygyny Threshold Model to Humans. Human Mating Patterns, eds. G. G. N. Mascie-Taylor and A. Boyce, pp. 213-230. New York.

1989. Marital Status and Reproductive Performance in Kipsigis Women: Re-Evaluating the Polygyny-Fertility Hypothesis. Population Studies 43:285-304. 
1992. Women's Strategies in Polygynous Marriage: Kipsigis, Datoga, and the East African Cases. Human Nature 3(1):45-70.

Brown, D. 1990. Human Universals. New York.

Burbank, V. 1994. Fighting Women: Anger and Aggression in Aboriginal Australia. Berkeley. Calame-Griaule, G. 1986. Words and the Dogon World. Philadelphia.

Cattell, M. 2003. Abaluyia. Encyclopedia of Sex and Gender, eds. M. Ember and C. Ember pp. 247-56. New York.

Chisholm, J., and V. Burbank. 1991. Monogamy and Polygyny in Southeast Arnhem Land: Male Coercion and Female Choice. Ethnology and Sociobiology 12:2, 91-113.

Clignet, R. 1970. Many Wives, Many Powers. Evanston.

Colson, E. 1961. Plateau Tonga. Matrilineal Kinship, eds. D. Schneider and K. Gough, pp. 36-95. Berkeley.

Crocker, W., and J. Crocker. 2004. The Canel: Kinship, Ritual and Sex in an Amazonian Tribe. Belmont CA.

de Munck, V., and A. Korotayev. 1999. Sexual Equality and Romantic Love: A Re-Analysis of Rosenblatt's Study on the Function of Romantic Love. Cross-Cultural Research 34:1-23.

Du Bois, C. 1960. The People of Alor. Cambridge.

Dupire, C. 1968. The Luo of Kenya. Washington DC.

Ekvall, R. 1968. Fields on the Hoof: Nexus of Tibetan Nomadic Pastoralism. New York.

Ember, M. 1985. Alternative Predictors of Polygyny. Behavior Science Research 10:249-81.

Feldman-Savelsberg, P. 1999. Plundered Kitchens, Empty Wombs. Ann Arbor.

Fortes, M. 1969. The Web of Kinship among the Tallensi. London.

Goldman, I. 1963. The Cubeo Indians of the Northwest Amazon. Urbana.

Goodenough, W. 1978. Property, Kin, and Community on Truk. Hamden.

Goody, J. 1976. Production and Reproduction: A Comparative Study of the Domestic Domain. New York.

1990. The Oriental, the Ancient, and the Primitive: Systems of Marriage and the Family in the Pre-Industrial Societies of Eurasia. Cambridge.

Gray, P. B., J. Flynn Chapman, M. H. McIntyre, T. C. Burnham, S. F. Lipson, and P. T. Ellison. 2004. Testosterone and Human Male Pair Bonding. Human Nature $15: 119-31$.

Gregor, T. 1985. Anxious Pleasures: The Sexual Lives of an Amazonian People. Chicago.

Hamadeh, N. 1999. Wives or Daughters. Intimate Selving in Arab Families, ed. J. Suad, pp. 141-73. Syracuse.

Harrell, S. 1997. Human Families. Boulder.

Hill, K., and M. Hurtado. 1996. Ache Life History. New York.

Hrdy, S. 1999. Mother Nature. New York.

Jankowiak, W. 1995. Introduction. Romantic Passion: A Universal Experience? ed. W. Jankowiak, pp. 1-19. New York.

2001. Harmonious Love and Passionate Love in an American Polygamous Community. Kinship in Contemporary America, ed. B. Wong, pp. 191-207. New York.

Jankowiak, W., and T. Fischer. 1992. A Cross-Cultural Perspective on Romantic Love. Ethnology 31:149-55.

Jankowiak, W., D. Nell, and A. Buckmaster. 2002. Managing Infidelity: A Cross-Cultural Perspective. Ethnology 41:85-101.

Jankowiak, W., and A. Ramsey. 2000. Femme Fatale and Status Fatale: A Cross-Cultural Perspective. Cross Cultural Research 34(1):57-69.

Kaplan, H. S., and J. B. Lancaster. 2003. An Evolutionary and Ecological Analysis of Human Fertility, Mating Patterns, and Parental Investment. Offspring: Human Fertility Behavior in Biodemographic Perspective, eds. K. W. Wachter and R. A. Bulatao, pp. 170-223. Washington DC.

Kilbride, P. 1994. Plural Marriage for Our Times: A Reinvented Option? Westport.

Landes, R. 1969. The Ojibwa Woman. New York.

Levine, N., and J. Silk. 1997. Why Polyandry Fails: Sources of Instability in Polyandrous Marriages. Current Anthropology 38(3):375-99. 
Levine, R. A. 1962. Witchcraft and Co-Wife Proximity in Southwestern Kenya. Ethnology 1(1):39-45.

Lizot, J. 1985. Tales of the Yanomami: Daily Life in the Venezuelan Forest. New York.

Low, B. 2000. Why Sex Matters: A Darwinian Look at Human Behavior. Princeton.

Madhavan, S. 2002. Best of Friends and Worst of Enemies: Competition and Collaboration in Polygyny. Ethnology 41(1):69-84.

Mason, K. 1982. Co-Wife Relationships Can be Amicable as Well as Conflictual: The Case of the Moose of Burkina Faso. The Canadian Journal of African Studies 22:615-24.

Mcllwraith, T. F. 1992. The Bella Coola Indians. Toronto.

Meekers, D., and N. Franklin. 1995. Women's Perceptions of Polygyny among the Kaguru of Tanzania. Ethnology 34(4):315-29.

Moran, M. 1990. Civilized Women: Gender and Prestige in Southeastern Liberia. Ithaca.

Murdock, G. P., and D. R. White. 1969. Standard Cross-Cultural Sample. Ethnology $8(4): 32-69$

Peachey, P. 2001. The Human Significance of the Conjugal Union. Lanham MD.

Schlegel, A. 1972. Male Dominance and Female Autonomy. New Haven. n.d. The Elementary Structure of Society. Unpublished paper.

Shackelford, T., M. Voracek, D. Schmitt, D. Buss, V. Weekes-Shackelford, and R. Michalski. 2004. Romantic Jealousy in Early Adulthood and in Later Life. Human Nature 15(3):283-300.

Shore, B. 1996. Culture in the Mind. Oxford.

Soloway, J. S. 1990. Affines and Spouses, Friends and Lovers: The Passing of Polygyny in Botswana. Journal of Anthropological Research 46:41-66.

Spencer, P. 1998. The Pastoral Continuum: The Marginalization of Tradition in East Africa. Oxford.

Strassman, B. 1997. Polygyny as a Risk Factor for Child Mortality among the Dogon. Current Anthropology 38:688-95.

Symons, D. 1979. Human Sexuality. Oxford.

Ware, H. (ed.) 1980. Women, Education and Modernization of the Family in West Africa. Canberra.

White, D., and M. Burton. 1988. Causes of Polygyny: Ecology, Economy, Kinship and Warfare. American Anthropologist 90:871-87.

Whyte, S. 1979. Wives and Co-wives in Marachi, Kenya. Folk 21-22:133-46. 
Copyright of Ethnology is the property of University of Pittsburgh. The copyright in an individual article may be maintained by the author in certain cases. Content may not be copied or emailed to multiple sites or posted to a listserv without the copyright holder's express written permission. However, users may print, download, or email articles for individual use. 